Third Place, Graduate division, MPD SME Student Poster Contest 2013

\title{
Novel method for the production of fine-grained tungsten carbide
}

\author{
Caelen D. Anderson \\ Colorado School of Mines, Golden, CO \\ CAAnders@mines.edu
}

Key words: Alkaline pressure leaching, Adsorption, Tungsten carbide

\section{Introduction}

Tungsten carbide is a valuable material used in a variety of different applications, including the manufacturing of cutting tools, bearings and as a cost-efficient alternative to industrial diamonds. Both the high hardness value (Mohs 9) and scratch resistance of this material make it a valuable commodity for use in the mining industry.

Usually, the production of tungsten carbide is a multistep process involving one or more of the following unit operations: hydrometallurgical digestion, solution purification, crystallization (as ammonium paratungstate), calcination, hydrogen reduction and carbon synthesis. The proposed three-step process eliminates three of these steps (crystallization, calcination and hydrogen reduction) by implementing a combination of hydro/ pyrometallurgical techniques. These include alkaline pressure leaching, carbon adsorption and carburization roasting.

By eliminating some of the intermediate processing steps, there is potential to reduce energy consumption and decrease overall operating costs.

\section{Methods and results}

Initially, alkaline pressure leaching with sodium carbonate $\left(\mathrm{Na}_{2} \mathrm{CO}_{3}\right)$ was employed to selectively leach tungsten, as tungstate $\left(\mathrm{WO}_{4}{ }^{2-}\right)$, from an industrial Scheelite $\left(\mathrm{CaWO}_{4}\right)$ flotation concentrate. Experimental variables included lixiviant $\left(\mathrm{Na}_{2} \mathrm{CO}_{3}\right)$ concentration, temperature and residence time. Experimental constants, based on previous work, were percent solids at $13 \mathrm{wt} \%$ and agitation at $400 \mathrm{rpm}$ (Queneau and Strathmore, 1969). Leaching results showed it was possible to extract $97 \%$ of the tungsten present. The most favorable conditions for leaching were determined: $2 \mathrm{M} \mathrm{Na}_{2} \mathrm{CO}_{3}$, temperature of $180^{\circ} \mathrm{C}$ and a residence time of 30 minutes.

Since the desired end product is fine-grained tungsten carbide, the most suitable adsorption medium for the solution purification step was activated carbon. Adsorption experiments were performed at three different $\mathrm{pH}$ values $(12.7,10.5$ and 8.5) for 12 hours, $300 \mathrm{rpm}$ at ambient temperature. Results showed it was possible to adsorb $41 \%$ of the tungstate onto the activated carbon matrix at the lowest $\mathrm{pH}, 8.5$.

In addition to eliminating multiple steps in the tungsten carbide production process, using activated carbon as the adsorbent provided the necessary carbon for the subsequent roasting step.

Thermodynamic analysis of the proposed process showed that in an inert atmosphere $\left(\mathrm{Ar}_{(\mathrm{g})}\right)$ it was theoretically plausible to produce tungsten carbide via carburization roasting.
Experimental roasting conditions were: $\mathrm{T}=700^{\circ} \mathrm{C}, 200 \mathrm{~cm}^{3} /$ min $\mathrm{Ar}_{(\mathrm{g})}$, with a residence time of two hours.

SEM/EDX analysis of the carburization product confirmed the presence of tungsten carbide.

The proposed flowsheet for this process is illustrated in Fig. 1.

\section{Conclusion}

This research has shown that it is possible to successfully produce a fine-grained tungsten carbide product using the proposed hydro/pyrometallurgical method.

\section{References}

Queneau, P.B., and Strathmore, R.B., 1969. "The kinetics of the dissolution of scheelite in alkaline aqueous solutions," Transactions of the Metallurgical Society of AIME, Vol. 245, pp. 2451-2459

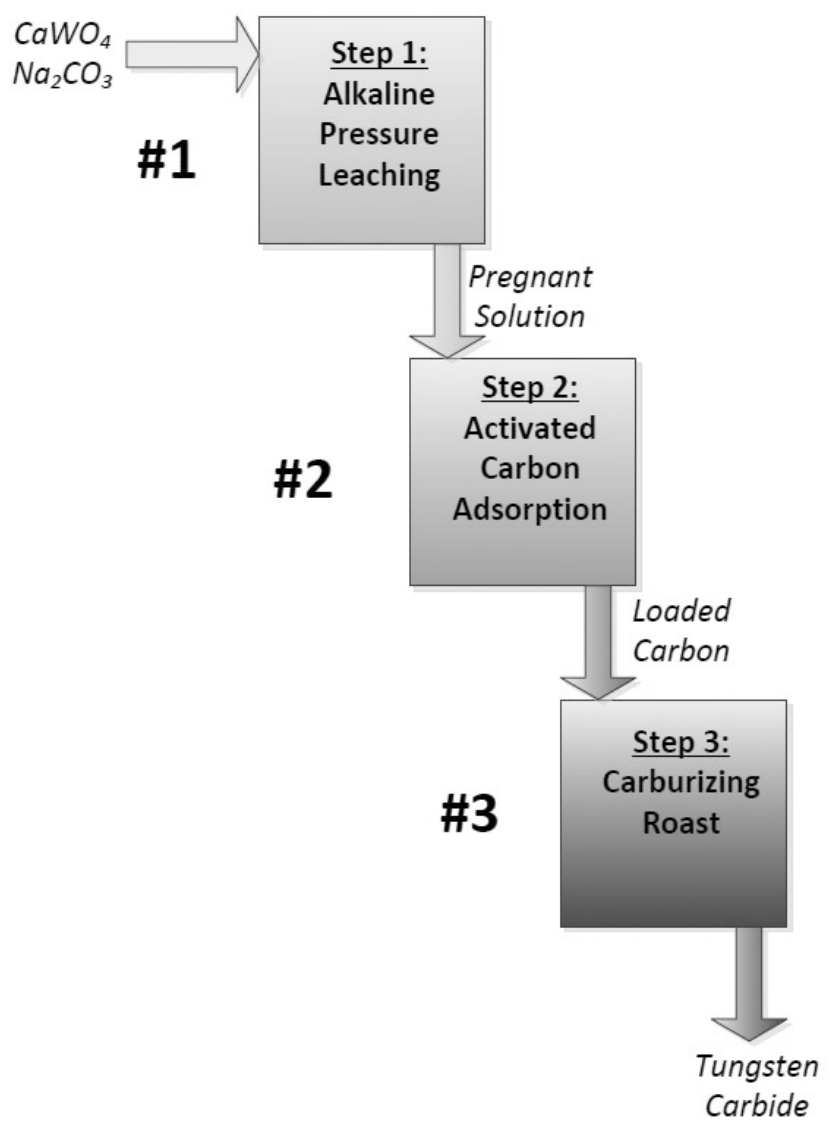

Figure 1-Novel process for the production of fine-grained tungsten carbide. 